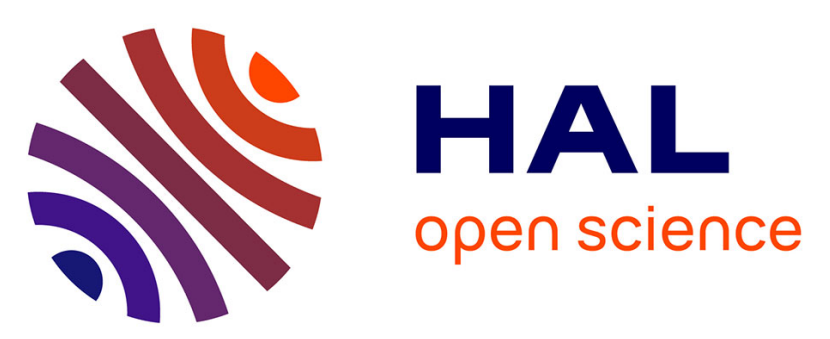

\title{
Assimilation of SST Satellite Images for Estimation of Ocean Circulation Velocity
}

\author{
Étienne Huot, Isabelle Herlin, Gennady K. Korotaev
}

\section{To cite this version:}

Étienne Huot, Isabelle Herlin, Gennady K. Korotaev. Assimilation of SST Satellite Images for Estimation of Ocean Circulation Velocity. IGARSS - Proceedings of IEEE International Geoscience and Remote Sensing Symposium, Jul 2008, Boston, United States. pp.847-850, 10.1109/IGARSS.2008.4779127 . inria-00583029

\section{HAL Id: inria-00583029 \\ https://hal.inria.fr/inria-00583029}

Submitted on 8 Jan 2014

HAL is a multi-disciplinary open access archive for the deposit and dissemination of scientific research documents, whether they are published or not. The documents may come from teaching and research institutions in France or abroad, or from public or private research centers.
L'archive ouverte pluridisciplinaire HAL, est destinée au dépôt et à la diffusion de documents scientifiques de niveau recherche, publiés ou non, émanant des établissements d'enseignement et de recherche français ou étrangers, des laboratoires publics ou privés. 


\title{
ASSIMILATION OF SST SATELLITE IMAGES FOR ESTIMATION OF OCEAN CIRCULATION VELOCITY
}

\author{
E. Huot I. Herlin $^{1,2,3} \quad$ G. Korotaev $^{4}$ \\ ${ }^{1}$ Institut National de Recherche en Informatique et Automatique - France \\ ${ }^{2}$ Université Paris-Est, CEREA, Joint Laboratory ENPC/EDF R\&D Paris-EST - France \\ ${ }^{3}$ Université de Versailles - Saint-Quentin-en-Yvelines - France \\ ${ }^{4}$ Marine Hydrophysical Institute - National Academy of Science - Ukrain
}

\section{INTRODUCTION}

The objective of this study is to compute the surface circulation velocity from oceanographic satellite acquisitions. The problem of apparent motion estimation from a sequence of images has been addressed by the image processing community for a long time. It can be tackled by solving a PDEs system composed of a conservation equation and a regularity hypothesis. On the other hand, data assimilation provides a mathematical solution to combine optimally observations and models; oceanographers use circulation models and data assimilation to estimate and forecast ocean' state.

We recently proposed [1] a new method for velocity estimation using the data assimilation framework: the available satellite images constitute observations of Sea Surface Temperature (SST) to be assimilated within a dedicated Image Model (IM). The major drawback of this approach was the lack of physical meaning of the evolution equations used in the $I M$. To take into account the physic of underlying processes, it is possible to consider estimated velocities as pseudo-observations and, further assimilated in a physical circulation model [2].

In this paper we propose to define a new Image Model taking into account the physical knowledge of ocean processes. This so-called Extended Image Model (EIM) is based on both image evolution properties and some physical equations expressing the evolution of the ocean state. Variational data assimilation is used to assimilate SST observations into the EIM and estimate ocean surface velocity.

\section{STATE OF THE ART}

Ocean surface velocity can be estimated by image processing techniques applied to sequences of satellite images. Classical methods [3] rely on a conservation equation designed for rigid or fluid motion $[4,5,6]$. But the conservation equation relies on the spatial and temporal derivatives of the image sequence, missing data on the acquisition damage estimation results. This is crucial with SST data that can be significantly occluded by clouds. Recently, the image processing community has been interested in data assimilation approaches [2, 7, 8], which provides an optimal way to deal with missing data. According to the same idea, we introduced [1] an Image Model, expressed in the image space, that expresses a link between SST and surface velocity:

$$
\left\{\begin{array}{l}
\frac{\partial T}{\partial t}+\nabla T \cdot \mathbf{v}=K_{T} \Delta T \\
\frac{\partial u}{\partial t}=0 \\
\frac{\partial v}{\partial t}=0
\end{array}\right.
$$

where the first equation is a simplification of the advection-diffusion formalism governing the transport of temperature of an uncompressible fluid; $K_{T}$ stands for the temperature diffusivity parameter. The two other equations constrain the evolution of the two velocity components $\mathbf{v}=(u, v)$ through an hypothesis of a constant velocity field. SST satellite data are assimilated into the $I M$ in order to estimate de surface velocity.

The major drawback of this approach is that the evolution equations of velocity have no physical interpretation.

\section{EXTENDED IMAGE MODEL}

To define an Extended Image Model with a physical meaning, it is necessary to address ocean modelizations done by oceanographers and numericians. As a first step, we are interested in shallow water models which link the 2D velocity of the merged layer of the ocean associated to the thickness $h$ of this layer. The EIM definition is based on the same transport equation of temperature as the $I M$ but the velocity evolution equations come from the shallow water model:

$$
\left\{\begin{array}{l}
\frac{\partial T}{\partial t}+\nabla T \cdot \mathbf{v}=K_{T} \Delta T \\
\frac{d u}{d t}-f v=g^{\prime} \frac{\partial h}{\partial x}+K_{v} \Delta u \\
\frac{d v}{d t}+f u=g^{\prime} \frac{\partial h}{\partial y}+K_{v} \Delta v \\
\frac{\partial h}{\partial t}+\frac{\partial(u h)}{\partial x}+\frac{\partial(v h)}{\partial y}=0
\end{array}\right.
$$


where $f$ is the Coriolis parameter; $K_{v}$ the viscosity coefficient; $g^{\prime}=g\left(\rho_{0}-\rho_{1}\right) / \rho_{0}$ the reduced gravity, with $\rho_{0}$ corresponding to the reference density and $\rho_{1}$ to the average density of the mixed layer.

\section{VARIATIONAL DATA ASSIMILATION}

Estimation of surface velocity is performed using a variational 4DVAR data assimilation scheme. Satellite SST acquisition is an observation of the state variable $T$, and $\mathbf{v}$ is estimated minimizing the discrepancy between the model's outputs and the observations. This is formulated as:

$$
\left\{\begin{array}{c}
\frac{\partial X}{\partial t}+F(X)=\varepsilon_{m} \\
X\left(t_{0}\right)=X_{0}+\varepsilon_{b} \\
Y=H(X)+\varepsilon_{o}
\end{array}\right.
$$

where the first equation is the evolution model (2), with state variable $X=(T, u, v, h)$; the second equation is the initial condition; and the third equation links the observations $Y$ to the state variables $X$ through the observation operator $H . \varepsilon_{m}, \varepsilon_{b}, \varepsilon_{o}$ stands for errors on model, initialisation and observations respectively.

In order to deal with a simpler problem, we are considering several assumptions: the model is consider to be perfect $\varepsilon_{m}=0$; we haven't any knowledge on the background $\varepsilon_{b}=0$; and observation errors are uncorrelated.

The data assimilation procedure consists in minimizing the energy functional $J$, that depends upon the control $X_{0}$ :

$$
J\left(X_{0}\right)=\frac{1}{2} \int_{\Omega, t}(H(X)-Y)^{\mathrm{T}} \mathbf{R}^{-1}(H(X)-Y) d x d y d t
$$

Minimization is performed using a quasi-Newtown involving the adjoint of system (3).

\section{CONCLUSION}

This paper presents a velocity estimation method applied to oceanographic image sequences. It is based on variational assimilation of image information into a dedicated image model. The method has two major advantages: it can deal with missing data due to cloud occlusion, and it takes into account some physical knowledge of the ocean circulation.

\section{REFERENCES}

[1] G. Korotaev, E. Huot, F.-X. Le Dimet, I. Herlin, S.V. Stanichny, D.M. Solovyev, and L. Wu, "Retrieving Ocean Surface Current by 4-D Variational Assimilation of Sea Surface Temperature Images," Remote Sensing of Environment, Special issue on data assimilation, (112), pp. 1464-1475, 2008, doi:10.1016/j.rse.2007.04.020.

[2] I. Herlin, E. Huot, J.-P. Berroir, F.-X. Le Dimet, and Korotaev. G., "Estimation of a motion field on satellite images from a simplified ocean circulation model," in Proceedings of International Conference on Image Processing, Atlanta, USA, October, 8-11 2006, IEEE, pp. 1077-1080.

[3] J. Barron, D. Fleet, and S. Beauchemin, "Performance of optical flow techniques," International Journal of Computer Vision, vol. 12, no. 1, pp. 43-77, 1994.

[4] D. Béréziat, I. Herlin, and L. Younes, "A generalized optical flow constraint and its physical interpretation," in Proceedings of CVPR'2000, 2000.

[5] T. Corpetti, E. Mémin, and P. Pérez, "Dense estimation of fluid flows," IEEE Transactions on Pattern Analysis and Machine Intelligence, vol. 24, no. 3, pp. 365-380, March 2002.

[6] X. Vigan, C. Provost, R. Bleck, and P. Courtier, "Sea surface velocities from Sea Surface Temperature image sequences," Journal of Geophysical Research, August 2000.

[7] F.-X. Le Dimet, "Assimage: Etude de techniques d'assimilations de données image dans des modéles de simulation de fluides géophysiques,” 2003-2006, Rapport finale pour l'ANR de l'ACI Masse de données.

[8] N. Papadakis, P. Héas, and E. Mémin, "Image assimilation for motion estimation of atmospheric layers with shallow-water model," in Asian Conference on Computer Vision, Tokyo, Japan, November 2007.

\section{ACKNOWLEDGEMENTS}

This work has been funded by the ECO-NET Egide program. 